\title{
Mental health courts: The key to decriminalizing the mentally ill?
}

\author{
Andrea Ennis
}

\section{Acadia University}

The deinstitutionalization movement of the late twentieth century saw vast closures of psychiatric hospitals. Despite intent to redirect patients towards community-based treatment, mental health services became progressively scarce. Many of those without access to adequate services were criminalized and increasingly became the responsibility of the criminal justice system, and prisons became surrogate psychiatric facilities. ${ }^{1}$ Overall rates of mental disorders among inmates vary; however, the average is around $16 \%$ for men and $31 \%$ for women; ${ }^{2}$ a rate that has steadily increased by approximately $10 \%$ per year over the past two decades. ${ }^{3}$ The increasing complexity of offender profiles and escalating need for mental health services places a strain on an already overburdened correctional system, leading to decreased access to mental health resources and unresolved issues that can elevate risk to reoffend. To halt this "revolving door", Mental Health Courts (MHCs) have been developed.

MHCs are problem-solving courts, in which judicial alternatives that promote wellbeing are employed in place of traditional criminal sanctions. ${ }^{5} \mathrm{MHCs}$ strive to reduce the number of mentally ill in prisons by diverting them to community-based rehabilitative treatment. MHCs thus revisit a goal of deinstitutionalization - connecting clients with mental health services in the community. Critics argue that governments have turned too readily to MHCs as a quick, visible solution, compounding the problem by ignoring substantial gaps in community services. ${ }^{6}$ Priority should be placed on 1) crime prevention, by addressing root causes of criminalization; and 2) revamping the civil mental health system. However, MHCs are a necessary part of a solution to decriminalize the mentally ill, as measures must be in place for them when they find themselves in contact with the law. Police initiatives that connect individuals with mental health agencies in lieu of pressing charges are a key interim step, and for those charged, MHCs provide another line of defense in decriminalization efforts.

\section{Structure of Mental Health Courts}

MHCs emerged in the United States in the mid-1990s. Canada was quick to follow suit, with MHCs established in most Canadian provinces, although primarily in urban centers. As MHCs are a relatively new phenomenon, they may not be well understood, and to complicate matters, there are various models that identify as an $\mathrm{MHC} .{ }^{4}$ Most MHCs are comprised of a collaborative and multidisciplinary team who provide mental health services and connections to community resources. ${ }^{7}$ In contrast to the regular court system, MHCs operate like a program, where in addition to the full-range of sentencing options, judges oversee the provision of treatment services, while also monitoring and imposing sanctions for non-compliance with the treatment plan and court-imposed conditions. Often, potential candidates are identified through the regular court system and presented with the option of transferring their charges to the MHC. Their decision to do so is voluntary; they either consent to participate in treatment through the MHC with the possibility of dismissed charges or a reduced sentence given compliance with the MHC program, or proceed through the regular court system. MHC eligibility varies extensively; some accept only those with a primary Axis I diagnosis (i.e. all psychiatric diagnoses, except mental retardation and personality disorders), ${ }^{8}$ while others accept a broader range of diagnoses. Most MHCs accept individuals with comorbid Axis I and substance abuse disorders, so long as the substance abuse disorder is not the primary diagnosis. Generally, candidates must have a significant and persistent mental illness that is believed to be a primary contributing factor in their criminal behavior. Eligibility also varies in terms of offence type. Some MHCs only accept those with minor offences, while others accept the full scale of offences. MHCs must also weigh mental health needs against public safety and therefore, some offences may be deemed inappropriate for diversion 
C $\quad$ via $\mathrm{MHC}$, particularly for violent and/or high profile cases when victim concerns or public outcry may be present. ${ }^{9}$

\section{Effectiveness of Mental Health Courts}

While there is certainly need for more research, the extant literature on $\mathrm{MHC}$ effectiveness suggests that participation in MHCs has a positive impact, leading to reductions in recidivism and alleviating strain on the correctional system. Studies in the US have found that those who successfully completed an MHC program were $22 \%$ less likely to reoffend and $50 \%$ less likely to reoffend violently compared to similar individuals processed through traditional courts. ${ }^{10}$ Similarly, two years after MHC completion, participants had lower offence rates than in the two years prior to entering the MHC. ${ }^{11}$ These promising results highlight the need to further research MHC effectiveness. This is particularly true in Canadian jurisdictions, as even less is known about the ability of MHCs to reduce recidivism and improve access to mental health resources. Such research would be timely, as recent legislative changes by the Canadian government have imposed "tough on crime" measures, such as mandatory minimum sentences and fewer conditional sentences for certain crimes, despite decades of research showing greater efficacy with least restrictive measures and supporting community-based rehabilitation. ${ }^{12}$ The expected increase of the inmate population only compounds the issue of strained resources, thus underscoring the need to divert those capable and willing through an MHC program.

Decriminalization of the mentally ill begins by addressing the root causes of criminalization, such as the state of the civil mental health system. Admittedly, MHCs cannot achieve their goal of redirecting clients towards communitybased services if those services are not readily available and adequately resourced. However, addressing these gaps is only the first piece of the solution, as those with mental illness are still being arrested, charged, and incarcerated at disproportionately high rates. To combat this issue, criminal justice agencies must work with government and community partners - sharing knowledge and integrating resources to make the common goal of decriminalizing the mentally ill attainable. Without the resources to offer adequate community mental health services, MHCs will undoubtedly face the same fate that was observed with deinstitutionalization - noble goals that could not fully be achieved due to lack of resources.

\section{References}

1. Lange S, Rehm J, Popova S. The effectiveness of criminal justice diversion initiatives in North America: A systematic literature review. Int J of Forensic Ment Health. 2011;10(3):200-214.

2. Steadman HJ, Osher FC, Clark Robbins P, Case B, Samuels S. Prevalence of Serious Mental IIIness Among Jail Inmates. Psychiatr Serv. 2009; 60(6): 761-765.

3. Schneider RD. Mental health courts and diversion programs: A global survey. Int J Law Psychiatry. 2010; 33(4):201-206.

4. Schneider RD, Bloom $H$, Heerema $M(2007)$. Mental health courts: decriminalizing the mentally ill. Toronto: Irwin Law; 2007

5. Wexler DB, Winick BJ. Therapeutic jurisprudence and criminal justice mental health issues. Ment Phys Disabil Law Rep. 1992; 16:225.

6. Kaiser, H. Too Good to Be True: Second Thoughts on the Proliferation of Mental Health Courts. Canadian Journal of Community Mental Health. 2010; 29(2):19-25

7. Slinger $E$, Roesch R. Problem-solving courts in Canada: A review and a call for empirically-based evaluation models. Int J Law Psychiatry. 2010; 33(4): 258-264.

8. American Psychiatric Association. Diagnostic and statistical manual of mental disorders (4th ed., text revision). Washington, DC: Author; 2000.

9. Toronto Mental Health Court. Roles of our various partners. Toronto: Toronto Mental Health Court; 2008. Available from: http://www. mentalhealthcourt.ca/pages/3/Partners.htm

10. McNiel D, Binder R. Effectiveness of a mental health court in reducing criminal recidivism and violence. Am J Psychiatry. 2007;164(9):1395-1403.

11. Hiday V, Ray B. Arrests two years after exiting a well-established mental health court. Psychiatr Serv 2010. 61(5):463-468.

12. Andrews D, Bonta J. The Psychology of Criminal Conduct. 5th edition. Cincinnati: Anderson Publishing; 2010.

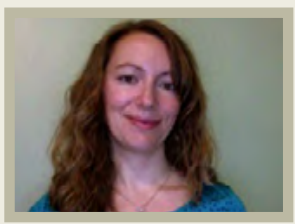

\section{Andrea Ennis}

Andrea Ennis has worked within the correctional system for the past eight years and is currently pursuing her MSc in Clinical Psychology at Acadia University. She received her BSc in Psychology from Memorial University of Newfoundland. Andrea's research focuses on the prevalence, assessment, and treatment of mental illness within the criminal justice system. 